This report was prepared as an account of work sponsored by the United States Government. Neither the United States nor the United States Atomic Energy Commission, nor any of their employees, nor any of their contractors, subcontractors, or their employees, makes any warranty, express or implied, or assumes any legal liability or responsibility for the accuracy, completeness or usefulness of any information, apparatus, product or process disclosed, or represents that its use would not infringe privately owned rights.

In the interest of prompt distribution, this LAMS report was not edited by the Technical Information staff.

Printed in the United States of America. Available from National Technical Information Service

U. S. Department of Commerce 5285 Port Royal Road

Springfield, Virginia 22151

Price: Printed Copy \$3.00; Microfiche \$0.95 


\section{Photon Emission from \\ Gases Induced by Tritium Beta Decay}

by

Charles E. Ragan III

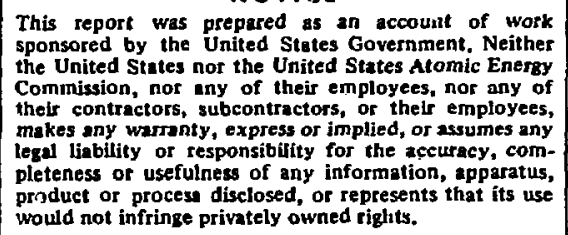

This report was prepared as an account of Work sponsored by the United Stetes Government. Neither Stes nor the United States Atomic Energy (a) makes any warenty, express or implied, or assumes any product or process disclosed, or represents that its use would not infringe privately owned rights. 


\title{
PHOTON EMISSION FROA GASES INDUCED BY TRITIUM BETA DECAY
}

by

Charles E. Ragan III

\begin{abstract}
The 11ght emitted when deuterlum $\left(D_{2}\right)$ and neon gas are bombarded with the beta particles from a tritlum $\left(\mathrm{T}_{2}\right)$ source $(\eta 2 \mathrm{mC1}$ ) has been studied using tritium absorbed in a titanium backing. When an RCA 8575 phototube was used as a detector, the 11 ght from the neon produced about 30 times as much anoje current 80 the ilght from the $D_{2}$. B1lters were used to determine that most of the 11 ght from $D_{2}$ has wavelengthe $<4000 \mathrm{~A}$, whlle most of the light from neon has wavelengths $>4000 \mathrm{~A}$. The photrtube anode current increased by a factor of 20 when the window Irterfor of a $D_{2}$-filled vessel was costed with a wavelength shificer, sodium salicylate. Pressure effects on the 11ght emitted were also studied up to $150 \mathrm{ps}$, and 1 was determined that the 11ght intensity does not decrease as fast as 1/pressure for either $D_{2}$ or neon. Viaual observation were made with the unaided eye, an RCA 8606 Image Intensifier (gain $\sim 10^{4}$ ), and a far ultraviolet-sensitive Image converter (gain $\sim 30)$; photographs were obtalned where possible using Polarold 3000-8peed film.
\end{abstract}

\section{MHERODUCTION}

Knowledge of the method in which deuter1um $\left(D_{2}\right)$ and tritium $\left(\mathrm{T}_{2}\right)$ gases $m i x$ to of obvious importance to the technclogy of fuston of these materials.

Presently no mixing expertments are betng performed using $D_{2}$ and $T_{2}$ gas because of the difficulty in handilng $T_{2}$. However, holographlc techniques ${ }^{1}$ are being used to atudy dymantc density varlations of such gaaes as helium injected Into nitrogen, and laser Raman opectroscopy techniques ${ }^{2}$ are being used to messure concentratione of these gases at a given point and time. The former method to not accurate enough to be uged in studying the mixing of $D_{2}$ and $T_{2}$, whle the latter method is too time consuming to allow a complete study of the mixing using different pressures and nozzle sizes.

An alternative method for studying $\mathrm{T}_{2}-\mathrm{D}_{2}$ mixing Is to observe the opatial and time-resolved light emlocion from the ger Induced by the critium beta rays. Tritlue has several mique properties that make it auttable to be used for this process. The beta particles are of ouch low energy ( $18 \mathrm{keV}$ maximum energy with an average energy of $5.6 \mathrm{keV}$ ) that the average range ${ }^{3}$ in $D_{2} 18<3.0 \mathrm{~mm}$ at one atn pressure. At higher pressures the esergy deposition Is even more localized, and light emlsaton from a point is an excellent Indication of the $T_{2}$ at that point. Tritium has a half-11fe of 12.4 years; thua, $1 \mathrm{~cm}^{3}$ at STP to equivalent to $2.6 \mathrm{Cl}\left(\sim 9.5 \times 10^{10}\right.$ disintegrations/sec).

In addition to studying the wixing of $D_{2}$ and $T_{2}$, the total 11ght emission Induced by $T_{2}$ beta raya can be used to indicate the presence of $T_{2}$ in $D_{2}$. Since the handling of gaseous $\mathrm{T}_{2}$ presenta tremendous safety problems, It was declded that a study of the feastbility of this method could be made using a thit layer of $T_{2}$ absorbed in titanium.

\section{TOTAL LIGHT OUTPUT MEASUREMERTS}

A. General

A source containing $\mathrm{T}_{2}$ absorbed in a thin layer of titanfum on a 1.5-1n. diam stainless steel disk was obtained from the Health Division. The total $T_{2}$ content of the suurce was $\sim 2 \mathrm{Cl}$. However, the 
effective beta-ray emission strength from the surface corresponded to a strength of $\sim 2 \mathrm{mCl}$. This estjmate of the strength was based on a measurement by Battleson ${ }^{4}$ of the current produced by the source in a sensitative Ionization chamber. The source was observed in a darkroom, and after allowing $20 \mathrm{~min}$ for the eyes to become dark-adapted, the source could be seen faintly when viewed in air.

An RCA 8575 photomultiplier tube with a peak response at 3850 A was then placed against the belI far and the entire assembly was covered with black cloth. ;The anode current of the phototube was measured with a Keithley 602 electrometer. When the bell jar was filled with neon, the anode current was approxfmately 30 times the current observed when the bell jar was filled with $D_{2}$.

Ir order to make more quantitative measurements and to study the effect of pressure on the light emitced, a pressure vessel shown In Fig. 1 was constructed. The vessel was pressure tested to 300 psi and was considered safe for operation up to $150 \mathrm{psi}$. F1gure 2 shows a photograph of the gas-filling system. The $T_{2}$ source was mounted on a holder which could be rotated from the outside of the vessel. The RCA 8575 phototube was placed against the Lucite window and measurements were made of the anode current vs the pressure for $D_{2}$ and neon. Before each filling, the vessel was evacuated to $\sim 50 \mathrm{f}$ pressure. Plots of the anode current vs pressure are shown for both gases in F1g. 3, along with a plot of $1 /$ pressure normalized to the neon output at one atm. The anode output from the $D_{2}$ gas has been multiplied by 30 , and the resulting curve is nearly identical to the neon curve. This factor of 30 difference implies only that more of the 11ght from neon is in the spectral region to which the phototube 18 sensitive. Figure 4 shows a plot of the relative efficiency of the RCA 8575 phototube as a function of wavelength. ${ }^{5}$

\section{B. Spectral Diatribution}

Kodak gelatin filters numbers 2B, 4, and 16 were used, along with the Lucite and quartz windows, to determine the spectral distribution of the radiation emitted by the two gases. Transmission vo wavelength is plotted in Fig. 5 for these filters, as well as for the Lucite and quartz wirdows. ${ }^{6}$ Table I gives the relative current readings for the neon and $D_{2}$ gases using the various filters and windows. AB

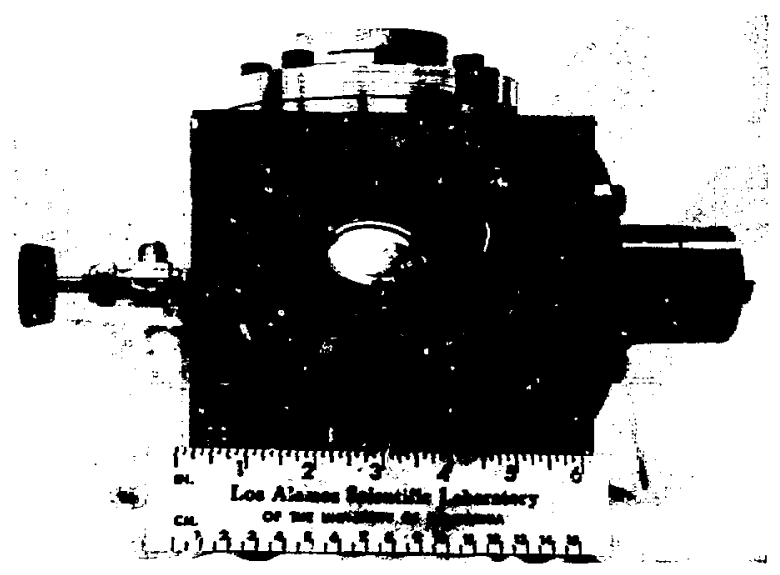

F1g. 1. Photographs of the pressure vessel showing the filling valve, the lucite window, and the tritium source mounted on the rotating holder.

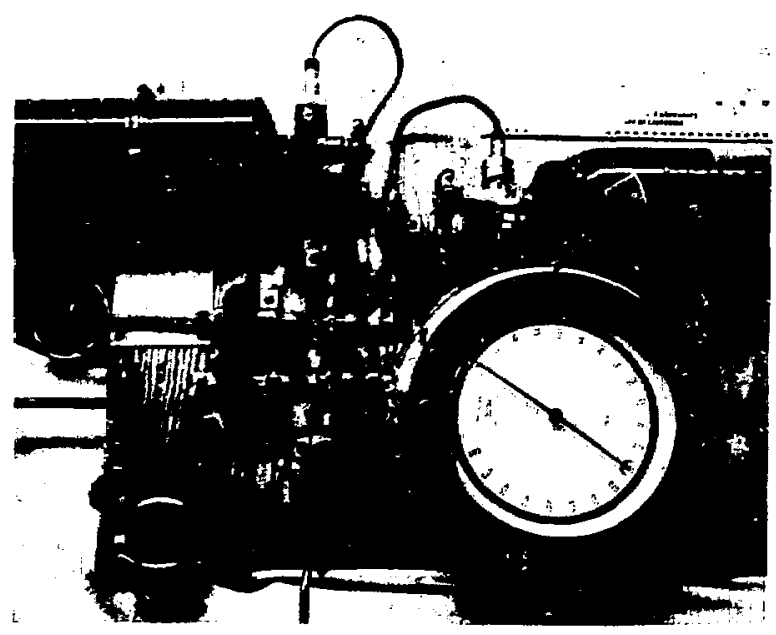

F1g. 2. Photograph of the gas-handling system showing the pressure gage and the gas bottles.

Indicated by this table, the major portion of the light from the $D_{2}$ is below $4000 \mathrm{~A}$, while approximately half of the light from neon has wavelengths $>4000 \mathrm{~A}$. There was no apparent change in the spectral distribution with pressure for either $D_{2}$ or neon. 


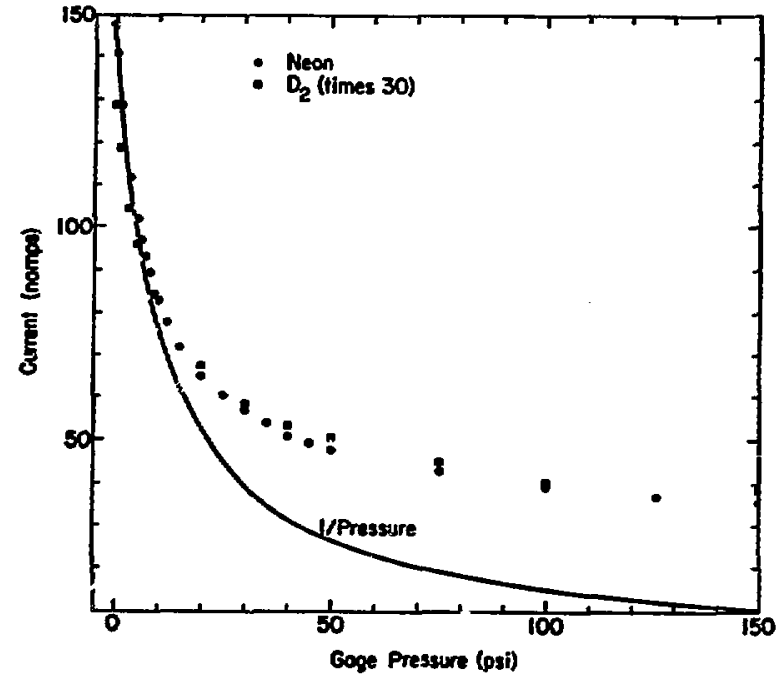

F1g. 3. Plote of the anode current in nampa ve the gage pressure in pat for both neon (O) and deuterlum (D). The anode currant recorded when the vessel was filled with deuter Ium hae been multiplied by 30 , and it is very almilar to the anode current observed when neon wes used. The colld curve 1a a plot of pressure ${ }^{-1}$ normalized to the neon current at 0 pal.

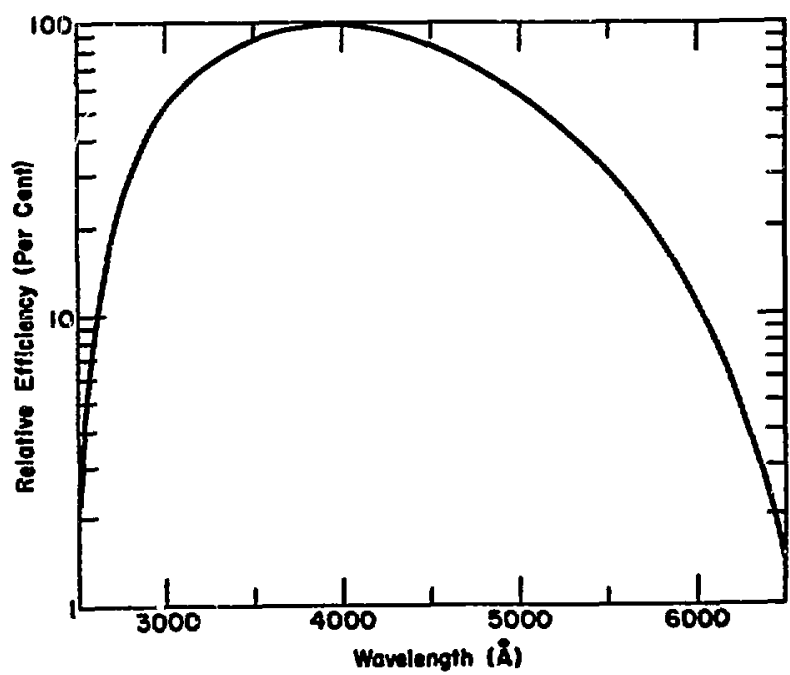

F18. 4. P1ot of the relative efficioncy in percent as a function of wevelength for en RCA 8575 photomultiplier tube (from Ref. 5).

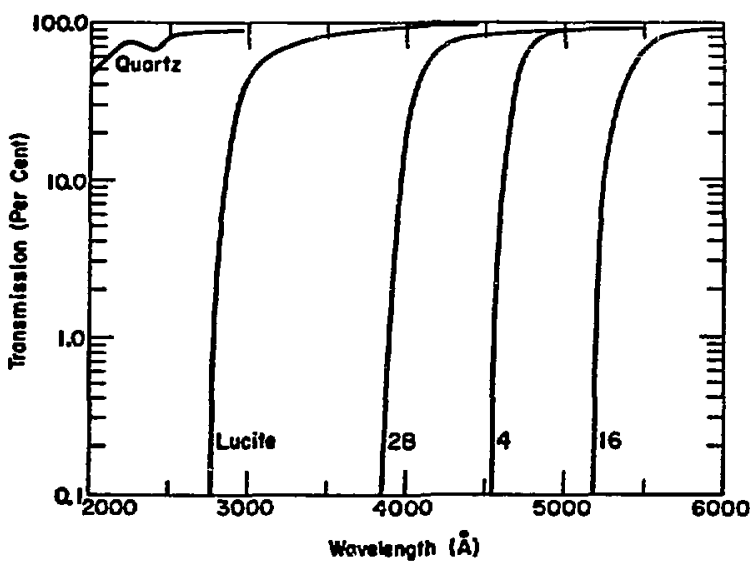

Ifg. 5. Plots of the trangmieston of the Kodak gelatin filters numbers $2 B, 4$, and 16 , along with the transmission curves for one-half in. of Lucite and quartz.

TABLE I

REILATIVE ANODE CURRENT FOR DIFFERENT FIITERS

\begin{tabular}{|c|c|c|c|}
\hline \multirow[b]{2}{*}{ F1lter } & \multirow{2}{*}{$\begin{array}{c}\text { Wavelength } \\
\text { Cutoff-10\% } \\
(8) \\
\end{array}$} & \multicolumn{2}{|c|}{ Gee } \\
\hline & & $\mathrm{D}_{2}$ & Beon \\
\hline $\begin{array}{c}1 / 2 " \text { Glaas } \\
1 / 2 \text { " Luc1te } \\
2 B \\
4 \\
16\end{array}$ & $\begin{array}{l}2050(50 \%) \\
2960 \\
3970 \\
4620 \\
5240\end{array}$ & $\begin{array}{r}100 \\
70 \\
30 \\
10 \\
2.1\end{array}$ & $\begin{array}{r}100 \\
90 \\
50 \\
39 \\
36\end{array}$ \\
\hline
\end{tabular}

When $D_{2}$ at atmospheric pressure was seeded by $B$ to $10 \%$ neon by volume, the anode current of the photomultiplier increased by 25 to $30 \%$. Then neon at atmospheric preseure was seeded with 8 to $10 \% \mathrm{D}_{2}$ by volume, the anode current decreased by 30 to $35 \%$. It thus appears that $D_{2} 18$ a very effective quencher for neon, but that no appreclable gain (factor of 2 to 10) in 1ight intensity can be obtained by seeding the $D_{2}$ with neon.

If a subatantial number of photons from $D_{2}$ had wavelengthe $<4000 \mathrm{R}$, then a wavelength ohifter coated on the Inside of the Lucite window should result in a marked Increase in the anode current of the phototube. Sodtun ealfcylate has an efficlency of $n 657$ for converting 11ght with wavelengthe from 300 to 3400 \& Into $1.1 \mathrm{ght}$ pesked at $4200 \mathrm{~A}$ with a half-width 
of $~ 350$ \& (see Ref. 7, p 214). When the Inside of the Lucite window was coated with a thin layer of sodium salicylate, the anode current increased by a factor of $\sim 20$. The anode current decreased with pressure in approximately the same manner as before.

\section{SPATIAL RESOLUTION EXPERIMENTS}

\section{A. General}

From the measurements described previously 1 t Is apparent that most of the light from $D_{2}$ is in the ultraviolet (uv). At pressures less than $\sim 1 / 3$ atm, various experiments ${ }^{7-9}$ show that $\mathrm{H}_{2}$ emits a continuous spectrum between 1600 and 4000 with a broad peak around $2300 \mathrm{~A}$. Other experiments ${ }^{7,10-12}$ at low pressure also show that $\mathrm{H}_{2}$ emits a line speetrum between 1100 and $1600 \mathrm{~A}$. The continuous spectrum is due to $a^{3} \Sigma_{g}^{+}+b^{3} \Sigma_{u}^{+}$transitions where $b^{3} \Sigma_{u}^{+}$ is an unbound state that dissoclates into two ground state hydrogen atoms. The line spectrum around $1600 \mathrm{~A}$ is due to $\mathrm{B}^{1} \Sigma_{\mathrm{u}}^{+}+\mathrm{x}^{1} \Sigma_{\mathrm{g}}^{+}$transitions (Lyman band), while the line spectra around $1200 \mathrm{~A}$ is due to $c^{1} \pi_{u}+x^{1} \pi_{g}^{+}$transitions (Werner band). (Lasing transitions have been observed in the Lyman band 10,11 and more recently in the Werner band 12,13 and are the most energetic lasing lines definitely observed.) Measurements by Berlman et a1. ${ }^{8}$ Indicate that flash tubes filled with $D_{2}$ emit $\sim 65 \%$ more photons than $\mathrm{H}_{2}$-filled tubes in the spectral region from 1800-350j A. This is due partially to the higher density of vibrational levels within a given electronic state for $\mathrm{D}_{2}$. This higher density of states gives rise to a larger total excitation cross section, as well as a more rapld radiative decay because of larger Franck-Condon factors.

Experiments on mercury vapor discharge lamps up to 285 atm indicate that the line character is replaced by a continuum as the pressure is increased. 14

\section{B. Apparatus and Procedure}

Polarold 3000-speed film and an osctlloscope camera with an $f / 1.8$ lens were used to photograph the light from the tritfum beta rays. Inftial photographs were obtained using a Lucite window in the pressure vessel. Figure 6 shows, a photograph of a front view of the source in one atm of neon gas obtained with a 15-min exposure. This source had previously been placed on an 0-ring and bombarded with deuterons. The position of the 0-ring, as

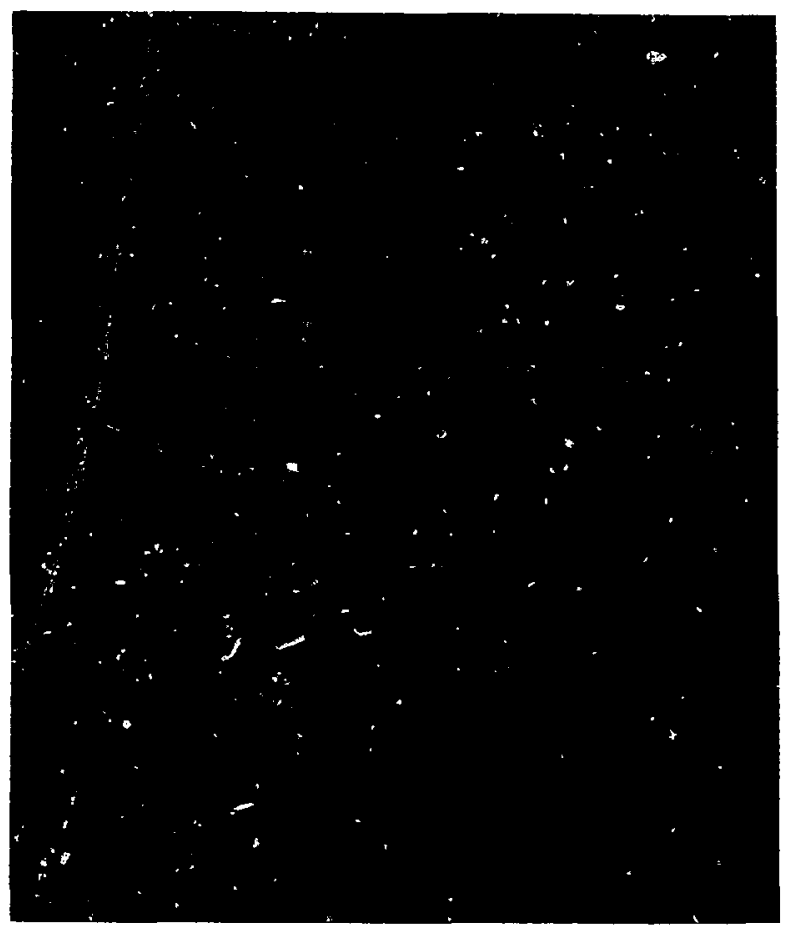

Fig. 6. A front view of the tritlum source in one atm of neon obtalned using a Polarold scope camera with an $f / 1.8$ lens and 3000-speed f1lm. The exposure time was 15 min (see (ext).

well as other detalls, are obvious in the photograph. A similar exposure for $14 \mathrm{~h}$ when the vessel was filled with $D_{2}$ ylelded a completely dark photograph. When the Lucite window was replaced with quartz and the source viewed edge-on to increase the Intensity, a 3-h exposure gave a faint picture using $\mathrm{D}_{2}$ gas.

In order to obtain photographs using shorter exposure times and with better contrast, an RCA 8606 Image intensifter and a 2-1/2-in.-diam f/0.85 lens were used. The image intensifier had a luminous $\operatorname{gafn}^{15}$ of $\sim 30,000$ and a photon gain of $\sim 10,000$, but the Input fiber optics would not transmit 11ghe below $3900 \AA$. The $f / 0.85$ lens was placed agatnst the quartz window of the pressure vessel and used to focus the light onto the intensifier. The same Polarold scope camera with 3000-speed film was used to photograph the output of the Intensifler. igure 7 shows a photograph of an edge view of the source in one atm of neon obtained with a $1 / 30-\mathrm{sec}$ exposure. Figure 8 shows a simflar photograph of the source in one atm of $D_{2}$ obtained using a 10-sec exposure. Two 


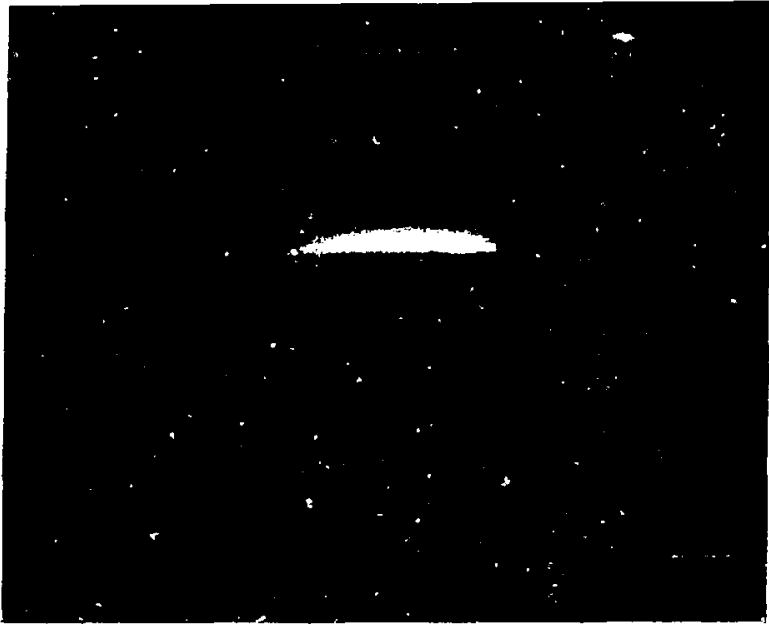

Fig. 7. An edge view of the tritium source in one atm of neon obtained during a 1/30-sec exposuie. A 2-1/2-in.-diam $f / 0.85$ iens and an RCA 8606 Image intensifler were used in conjunction with a Polarold scope camera and 3000-speed film to obtain this photograph.

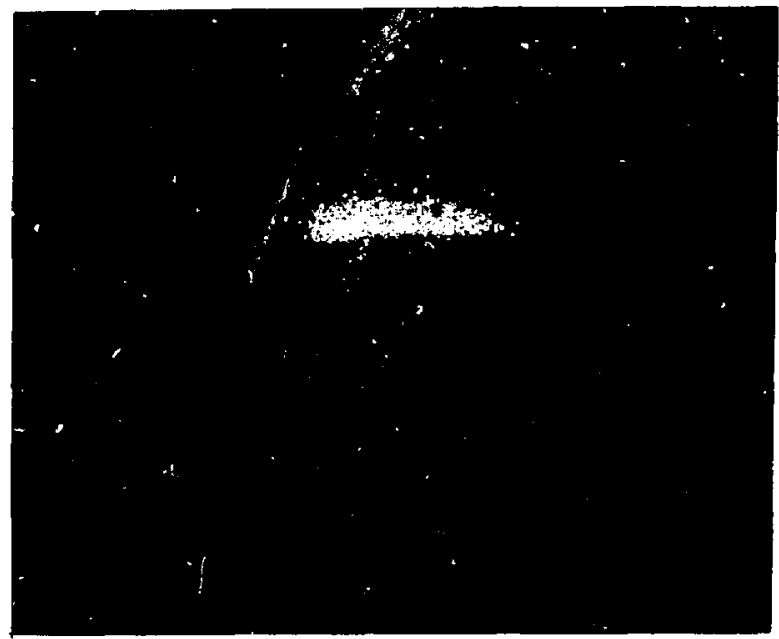

Fig. 8. An edge view of the tritium source in one atm is deuterlum obtained during a 10-sec exposure. A 2-1/2-in.-d1am f/0.85 lens and an RCA 8606 Image intensifter were used In confunction with a Polaroid scope camera and 3000-speed film to obtain this photograph. Notice the spots due to the large dark current and the range of the beta rays compared with those in Fig. 7 . differences to be noted are the greatly increased notse for the $10-\sec$ exposure and the increased range of the beta rays in $D_{2}$. The difference in exposure times by a factor of 300 is partially due to the fact that the intensifler will not transmit below $3900 \mathrm{z}$.

In order to see what light could be observed from $D_{2}$ in the $u v$, an $E M R$ Image converter tube with a phocon gain of $\sim 30$ was obtalned. This tube had a curved faceplate of 11thfum fluoride (transmission to $1040 \mathrm{~A})$ and a cestum fodide photocathode with a peak quantum efficiency of $29 \%$ at 1219 A decreasing to $0.6 \%$ by $1800 \AA$. In order to focus 1 ight at these wavelengths a Cassegrain-type reflecting lens ( $~$ 4-cm diam) was designed using sphericel surfaciss and the construction was carried out by group M-5. The aluminum surfaces of the miriors were coated with $\mathrm{MgF}_{2}$ as described by Hutcheson et al. ${ }^{16}$ in order to reflect $\sim 85 \%$ of the light down to $1200 \mathrm{~A}$. An Intense mercury uv source was used to ald in fosusing the light onto the EMR tube. Figure 9 shows a photograph of the mirrors and supports used in the lens, and Fig. 10 shows the entire lens system with the EMR tube mounted on the end. The complete system out to the EMR tube was evacuated and filled with $D_{2}$. A 14-h exposure resulted in no vistble photograph. It appears that the integrated intensity of the 11ght in the 1200 to 1800 \& regton of the spectrum is not very large. However, the solid angle of this lens is $\leqslant 10 \%$ of that of the $f / .85$ lens and the response of the EMR tube cuts off rather sharply. The EMR tube was removed and replaced with a quartz window, and the RCA 8606 was placed at the focus of the lens. As expected, a poorer picture resulted than obtained previously with the source in $D_{2}$ because of the decrease in solid angle.

\section{CONCLUSIONS}

From these measurements it appears that most of the photons from $D_{2}$ bombarded with $T_{2}$ beta rays are between 1600 and 4000 A. Special optics are needed In this spectral region, but because of solid-angle and field-of-view problems in the reflecting optics, a dichromatic doublet of fursed silica and elther sapphire, lithium fluoride, or $\mathrm{MgF}_{2}$ would probably be more useful. 17 


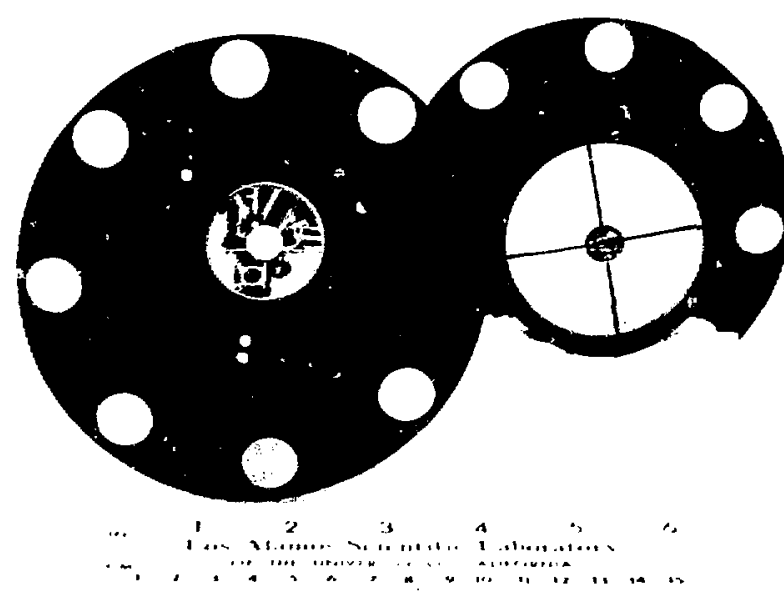

F1g. 9. Photograph of the $\mathrm{MgF}_{2}$-coated mirrors and supports used in the reflecting optics system.

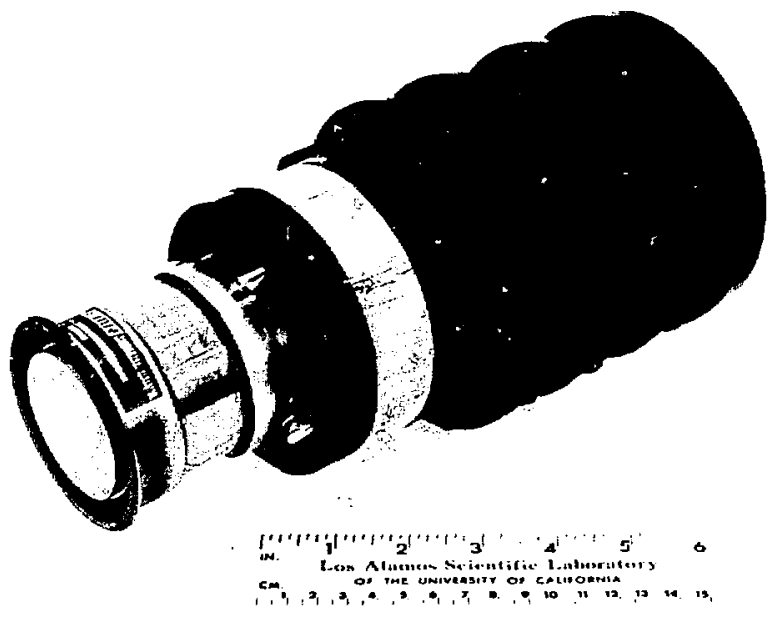

Fig. 10. The assembled lens system with the EMR Image converter tube mounted at the focal plane. The output fiber optics of the tube can be seen.

If one assumes that the photon emission from gaseous $T_{2}$ varles inversely as the pressure, then the "effective" disintegration rate of $T_{2}$ for 11ght production is independent of the pressure. The calculations of Miles et al. ${ }^{18}$ Indicate that for electrons with energles $>0.1 \mathrm{keV}, 33 \mathrm{ev}$ are required to produce an Ion patr; therefore, each $\mathrm{cm}^{3}$ of $\mathrm{T}_{2}$ at STP produces an average of $1.7 \times 10^{13}$ Ion palrs/sec. If one assumes that one photon results from each ion pair produced, then $1.7 \times 10^{13}$ photons/ sec will be produced from each $\mathrm{cm}^{3}$ of $\mathrm{T}_{2}$. For a lens system accepting $0.1 \%$ of the total 11ght (1-1n.dlam lens 8 in. away) with no reduction in size and with a $50 \%$ transmission, $8.5 \times 10^{9}$ photons/sec would be focused onto $1 \mathrm{~cm}^{2}$. For an image tube with a photon gain of only $10^{3}$ and for $5500 \mathrm{~A}$ ( $2.3 \mathrm{eV}$ ) output IIght, the output would be $31 \mathrm{ergs} / \mathrm{cm}^{2} / \mathrm{sec}$. If film with a sensitivity similar to that of Polarold 3000-speed $\left(5 \times 10^{-3} \mathrm{erg} / \mathrm{cm}^{2}\right.$ to produce a reflection density of 0.5 in the print) were used, then exposure times of $\sim 1 / 6 \mathrm{msec}$ could be used. Dilute concentrations of $\mathrm{T}_{2}(<1 \%)$ could be observed using msec framing rates if Image intensiflers with gains of $10^{5}$ were used.

The above discussion assumes that the film was placed against the output fiber optics of the image tube. If an additional lens were used to focus the output of the intensifier onto the f1lm, the light Intensity would be reduced by a factor of 10 to 100 . The above discussion also assumes 1 photon per ton pair. The results of the phototube measurements Indicate that in the region above $2800 \mathrm{~A}$, there are 12 to 120 photons emitted per disintegration, or 0.07 to 0.7 photons emitted per Ion pair. However, In view of the measurements with sodium salicylate, a more reasonable estimate of the number of photons per Ion pair with wavelengths $>1600 \mathrm{~A}$ is between one and ten.

For gaseous tritium each beta decay would result in a ${ }^{3} \mathrm{He}^{+}$ion recolling with $\sim 3 \mathrm{eV}$. Additional photons would result from the recombination of this Ion that would probably not be observed when using $T_{2}$ absorbed in titanium. In a discharge tube at a pressure of 600 torr, helium emits a continuous spectrum between 1600 and 4000 \& (see Ref. 7, P 103). Contributions from this effect may be observed by Battleson of Sandia, Liverwore ${ }^{4}$ when he performs some of his planned experiments using gaseous $\mathrm{T}_{2}$ in a chamber with a sapphire window. 


\section{REFERENCES}

1. D. M. Drake and M. A. Winkler, Los Alamoe Sclentific Laboratory, private communication, January 1973.

2. D. L. Hartley, "Bxperimental Gas KIxIng Study Ut111a1ng Laser Raman Spectroscopy," Sand1a Leborator1es report SCL-DC-710023, March 1971.

3. L. Katz and A. S. Penfold, 'Range-Bnergy Relatlong for Electrons and the Determination of Beta-Ray End-Point Energies by Abeorption," Rev. Mod. Phys. 24, 28 (1952).

4. R. Battleson, Sandia IIvermore Laboratory, private connunication, Harch 1973.

5. R.C.A. 8575 Data sheet (Barrieon, N. J., 1965).

6. L. C. Smith, Loe Alamos Sclentific Laboratory, private communication, November 1972.

7. J.A.R. Sameon, Techniques of Vacum U1treviolet Spectroscopy (John WIley and Sons, Inc., New York, 1967).

8. I. B. Berlman, 0. J. Steingraber, and H. J. Beneon, "Hydrogen Flash Lampe," Rev. Sc1. Instr. 39,54 (1968).

9. A. S. Cool1dge, "Experimental Verification of the Theory of the Continuous Spectra of $\mathrm{H}_{2}$ and $\mathrm{D}_{2}$ " Phya. Rev. 65, 236 (1944).

10. R. W. Waynant, J. D, Shipman, Jr., R. C. E1ton, and A. W. Al1, "Vacuum U1traviolet Laser Emlssion from Molecular Hydrogen," Sppl. Phys. Lett. 17. 383 (1970).
11. R. T. Hodgaon, "Vacuum-U1traviolet Laser Action Observed in the Lyman Banda of Molecular Hydrogen," Phys. Rev. Lett. 25, 494 (1970).

12. R. W. Waynant, "Observations of Gain by Stimulated Bnission in the Werner Band of Molecular Hydrogen," Phys. Rev. Lett. 28, 533 (1972).

13. R. T. Hodson and R. W. Dreyfus, "Vecuum-uv Iaser Action Observed in $\mathrm{H}_{2}$ Werner Bands: 1161-1240 A," Phys. Rev. Lett. 28, 536 (1972).

24. L. R. Xoller, U1traviolet RadLation (John Wiley and Sons, Inc., New York, 1965) 2nd ed., p 43.

15. Photoelectronlc Imaging Deviceg, Vol. 1 and 2, Bd. by L. M. Biberman and S. Nudelman (Plenum Preas, New York, 1971).

16. E. T. Hutcheson, G. Hase, and J. T. Cox, "Effect of Deposition Rate and Substrate Temperature on the Vacuum U1traviolet Reflectance of $\mathrm{MgP}_{2}$ - and L1F-Overcoated Aluminum Hifrorb," App1. Opt. 11. 2245 (1972).

17. J. Bennes and I. Dunkelman, "U1trav1olet: Technology," in The Mdale ultraviolet, Ito Science and Technology, A.B.S. Green, Ed. (John Wley and Song, Inc., New York, 1966).

18. T. T. Miles, R. Thompeon, and A.E.S. Green, "Electron-Impact Cross Sections and Bnergy Deposition in Molecular Hydrogen," J. Appl. Phys. 43, 678 (1972). 